\title{
Supporting the education and well-being of children who are looked-after: what is the role of the virtual school?
}

\author{
Helen Drew $^{1} \cdot$ Robin Banerjee ${ }^{1}$
}

Received: 19 October 2016 / Revised: 17 January 2018 / Accepted: 12 March 2018 /

Published online: 28 March 2018

(C) The Author(s) 2018

\begin{abstract}
The Children and Families Act (2014) placed a statutory responsibility on local authorities in the UK to establish a virtual school headteacher with the role of championing the education of all children looked-after within that authority. The current research was designed to illuminate how virtual schools are currently supporting educational outcomes for children looked-after, not only through educational interventions, but also through supporting broader psychological factors that might impact on attainment such as attachment, relationships and mental health. Virtual school headteachers from 29 local authorities completed an online survey about the services they provided to three target groups - children looked-after, foster carers and schools - with a particular focus on the transition years from primary to secondary school, which have been identified as being a difficult time for children looked-after. Using inductive thematic analysis, four overarching themes to service provision were identified: enhanced learning opportunities, specific transition support, well-being and relationships, and raising awareness. Direct work, interprofessional working and the development of supportive environments, particularly guided by attachment theory, were identified as important areas of practice. Practice is discussed in relation to resilience and ecological systems theory and suggestions for future research are identified.
\end{abstract}

Keywords Virtual schools · Children looked-after · Educational attainment · Well-being · Attachment

\section{Introduction}

Children looked-after (CLA) are children and young people under the age of 18 who are accommodated by local authorities (local government departments in England) for a period of $24 \mathrm{~h}$ or more, either voluntarily in agreement with parents or as a result of a care or placement

Helen Drew

H.M.Drew@sussex.ac.uk

1 School of Psychology, University of Sussex, Falmer, Brighton BN1 9QH, UK 
order obtained through the courts (Children Act 1989). They may be placed into the care of another parent, foster carers (including relatives and friends), in residential care, in secure accommodation or with prospective adopters. Currently, three quarters of CLA are placed with foster carers, meaning they are cared for in a family-based setting (Department for Education [DfE] 2017a). The educational needs of this group of children have often received less attention than other aspects of care planning (Harker et al. 2004; Jackson 1989; Morgan 1999), yet the educational under-attainment and sometimes inadequate educational experiences of CLA has been well documented (Fletcher-Campbell 1998; Goddard 2000; Jackson 1988, 1994; Jackson and Sachdev 2001). As part of the response to raise the profile of education and improve attainment in England, a statutory obligation has been placed on local authorities to establish a 'virtual school' headteacher (VSH) to champion the education of CLA in their authority's care (Children and Families Act 2014). With a clear remit to improve educational outcomes by monitoring progress and working with partners to ensure the educational needs of CLA are better met, virtual schools (VS) are well placed to offer both direct and strategic support to foster positive educational outcomes for young people in the care system.

There are large gaps, however, in our understanding of the diversity of current VS provision and particularly the extent to which such provision addresses the broader psychological factors likely to be affecting educational attainment in this group, such as mental health, attachment, peer relationships, socio-behavioural and emotional well-being. The present study aims to address these gaps, with a specific focus on if, to what extent and how VS are addressing such factors in their efforts to promote educational attainment in CLA, along with VS perceptions of effective provision, and facilitators to achieving this. We give particular attention to the transition years from primary to secondary school in England, encompassing the age range of 10 to 15 years, since this is a key vulnerability period for the development of sociobehavioural and socio-emotional problems (Rice et al. 2011; West et al. 2010) and over a third of CLA are currently within this age range (DfE 2017a, p. 5).

\section{Explaining educational underachievement in CLA}

In 2016, at the end of primary school at age 11,25\% of CLA attained the nationally expected standard or above in reading, writing and mathematics (compared to $54 \%$ for non-CLA), but by the end of secondary school, only $13.6 \%$ achieve the expected benchmark of five $\mathrm{A}^{*}-\mathrm{C}$ grade GCSEs (the exams taken aged 15-16), below the 53\% of non-CLA who achieved this level (DfE 2017b). While many factors may account for this apparent decline relative to peers, school outcomes are closely related to issues of mental health and well-being (Public Health England 2014). Understanding and intervening to address underlying psychological factors may be a crucial platform for the success of VS in tackling under-attainment among CLA.

Many children entering care have experienced severe prior disadvantage, disruption, abuse and/or neglect and can correspondingly display a profile of significant maladjustment across many aspects of development (Bazalgette et al. 2015a; Berridge 2012; Fisher 2015). These pre-care experiences are associated with poorer educational outcomes (O'Higgins et al. 2015). Sixty percent of children become looked-after as a result of abuse or neglect (DfE 2016), and often children will have experienced more than one type of maltreatment (Trickett et al. 2011). Maltreatment has been associated with a range of negative outcomes that may impact on educational attainment, including mental health problems (Tarren-Sweeney 2008), difficulties with relationships and interpersonal skills (Darwish et al. 2001; Egeland et al. 2002; Parker and 
Herrera 1996; Salzinger et al. 1993) and less prosocial, more aggressive, disruptive or withdrawn behaviour (Alink et al. 2012).

Special educational needs and disability (SEND) also have a huge effect on attainment (DfE 2017a) and are much more common for CLA (just over 57\% are identified as having such needs) than for the total population with SEND (just over 14\%) (DfE 2017b, Table 4a). It is noteworthy that the most common primary need is 'social, emotional and mental health'. In primary schools up to age 11, about $41 \%$ who are receiving the highest level of SEND support (in England having a 'statement' or Education and Health Plan (EHC)) have this as their primary need compared to just over $13 \%$ with moderate learning disabilities and just under $20 \%$ with speech, language and communication needs. In secondary schools, this rises to almost 50\% (DfE 2017b, Table 4b). This is a very different profile to those not looked-after with SEND, where only just over $12 \%$ of those with statements or EHC plans have 'social, emotional and mental health' as their primary need (DfE 2016). It reflects the high level of mental health difficulties experienced by CLA, the frequency and severity of which more closely resembles clinic-referred populations than the population at large (Meltzer et al. 2003; Tarren-Sweeney and Vetere 2014), and is far higher than even the most socio-economically disadvantaged children living in private households (Ford et al. 2007).

Attachment issues are also related to educational attainment. These have been estimated to affect a quarter of all children, and are associated with a range of socio-economic risk factors, but they are particularly identifiable in CLA (Bergin and Bergin 2009; Cicchetti et al. 2006; Cyr et al. 2010; Howe and Fearnley 2003). Children with insecure or disorganised attachments have been found to have a number of difficulties relative to their securely attached peers, many of which can impact directly or indirectly on learning and attainment, including more externalising problems (Fearon et al. 2010); some increase in internalising problems (Madigan et al. 2012); less resilience when faced with challenge (Matas et al. 1978); lower competence with language (van Ijzendoorn et al. 1995); self-regulation difficulties, particularly social self-control (Drake et al. 2014); and more problems with peer relationships in middle childhood (Seibert and Kerns 2015).

The transition from primary to secondary school is a time when many such difficulties can come to the fore. Many CLA may need holistic, individualised, enhanced transition support (Brewin and Statham 2011) since lower academic attainment, lower self-esteem and behaviour problems impact negatively on systemic transitions (Anderson et al. 2000; West et al. 2010), as can problems with social skills and making friends, which have been identified as issues for CLA (Brewin and Statham 2011; Luke and Banerjee 2011). Children with insecure attachments or those who have already experienced instability through placement changes are also more likely to experience problems during periods of further change (Dent and Cameron 2003). Bullying is also known to impact negatively on a successful transition (Evangelou et al. 2008), and CLA can be up to two times more likely to experience bullying (Daly and Gilligan 2005), while children with SEND have also been found to experience more bullying during the transition period (Evangelou et al. 2008).

\section{Virtual school context and remit}

Although the key aim of VSHs is to champion the education of CLA in their authority's care, policy and inspection frameworks have highlighted the importance of VSHs supporting emotional well-being. The recent Social Care Annual Report carried out by Ofsted, which in England is the organisation responsible for inspecting schools, local authorities, children's 
home and fostering services, highlighted examples of good practice where virtual schools used targeted funding effectively to support children's emotional well-being and mental resilience through such provision as counselling, play therapy and music lessons (Office for Standards in Education (Ofsted) 2016, para 105). The Handbook for VSHs also reflects this, with a section focussed on 'Emotional health and well-being' and the links this has with attainment and progress (Rees and The National Virtual School Network 2015, p. 21).

As the role of the virtual school continues to evolve and change, one important development has been the recent establishment of the National Association of Virtual School Headteachers (NAVSH) which has enabled VSHs to formulate collective strategic priorities and provide a unified professional response to incoming legislation and proposed changes affecting CLAs' education. One of their key priorities is to support schools in implementing the recent National Institute for Health and Care Excellence (NICE) Guidelines on Attachment (NICE 2015). This emphasises the importance of VSHs working with others to ensure that children and young people with attachment difficulties are effectively supported in educational settings (NICE 2015, Section 1.2). The NAVSH's commitment to supporting attachment, emotional health and well-being, and resilience is also stated in the information they provide to schools on their website (navsh.org., "Emotional Health \& Wellbeing" n.d.).

\section{Resilience within an ecological systems framework}

Our analysis of VS practice across these transition years is framed by a resilience perspective, where resilience is viewed as a dynamic process involving complex interactions between personal qualities of individuals, supportive interpersonal relationships and broader structural and community support across the life course (Hart et al. 2015; Masten 2001; Rutter 2007, 2012). Identifying how virtual school practice might support resilient outcomes by working at different levels both with and around the child is important, given that care level factors such as earlier entry into care and placement stability (Sebba et al. 2015) through encouragement from one key supportive adult at the interpersonal level (Jackson and Sachdev 2001) have been found to influence better than expected educational outcomes. Ecological systems theory (Bronfenbrenner 1979; Bronfenbrenner and Morris 2006) situates development within multiple levels of embedded systems, ranging from the proximal child environments known as microsystems (e.g. foster family, school, peer group) and the interconnections between them (the mesosystem), to more distal structures within the exosystem (e.g. education and political systems). This provides a valuable theoretical framework for identifying the different levels at which the virtual school may be intervening to support CLA across this age range.

Although VSHs are required to champion the education of CLA, as if they all attended a single school, in reality they are dispersed across many schools and alternative educational settings, both within and outside of the local authority responsible for their care. The VS can therefore be expected to play both a direct and a strategic role: supporting multi-agency approaches to raise the profile of education alongside other aspects of care planning, to working closely with individual children, foster carers and schools. Promising interventions at each level are reviewed below, specifically: (a) direct interventions with children lookedafter; (b) support at the microsystemic level, particularly for schools and carers in working with children looked-after; and (c) work at the mesosystemic and exosystemic levels including awareness raising, training and multi-agency work with other stakeholders (e.g. educational psychology, social care services, health providers). 


\section{Virtual school strategies and interventions}

Specialist direct work with CLA may be provided by the VS, as funding such specialist input within every single school would not be cost effective. Such centrally provided direct work may take many forms; examples include a phone line to support homework and one-to-one tutoring, both of which were found to be effective in the pilot of virtual schools (Berridge 2009). One-to-one mentoring has also been used prior to the establishment of virtual schools by some local authorities (Holland et al. 2005), with successful outcomes for older adolescents preparing to transition out of care (Osterling and Hines 2006), but whether it is employed by VSHs or used to support transitions between schools has not been researched.

Much of the work of virtual schools is likely to involve working with microsystems around the child, since these are the environments within which most children build their relationships and where they spend the most time. Identifying the role that the VS plays in supporting carers is vital since there is a recognised need to challenge and overcome low expectations among some professionals and carers (Jackson and Sachdev 2001; Tideman et al. 2011), and the foster care setting plays an important part in children's educational outcomes (e.g. Harker et al. 2004; Jackson et al. 2005; Martin and Jackson 2002). Schools are also a crucial microsystem, since they provide the daily learning environment for most CLA, have the potential to enhance resilience and provide an important 'complementary secure base' (Daniel et al. 1999; Dent and Cameron 2003; Gilligan 1998). The important role schools play in supporting social and emotional well-being is emphasised in good practice guidelines (NICE 2008, 2009), and the connections that whole school approaches and school ethos have with pupils' social experiences, overall school attainment and absence have been evidenced (Banerjee et al. 2014). All maintained schools have a duty to appoint a member of staff called a 'designated teacher' (DT) and 'designated governor' to promote and oversee the educational achievement of CLA within their school, and thus, relationships between them and the virtual school are likely to be particularly important.

Virtual schools have the potential to influence school ethos and to use their expertise to raise awareness of the impact of early trauma, attachment and mental health on learning in school. Developing an awareness of attachment in school has been the focus of several initiatives and publications (Bombèr 2007, 2011; Rose 2014) and is viewed as an important element in core teacher training and professional development (Geddes 2006). However, little is documented with regards to how VS raise awareness of attachment within schools, despite its high profile in the aims of their national association.

At a more strategic, mesosystemic level, all agencies need to work together to positively impact educational outcomes. Multi-agency training to raise awareness of the issues affecting CLA is acknowledged good practice (NICE 2010), so capturing the breadth and focus of any training delivered by virtual schools is important. The fact that VSHs have responsibility for managing the Pupil Premium Plus (PPP) funding, which is additional government funding to support the raising of attainment in CLA, also means they have the capacity to use this creatively through targeted or pooled spending (DfE 2014b). Much of the decision-making regarding the spending of this budget will be made at Personal Education Plan (PEP) meetings which are statutory school-based meetings where children, carers, social workers and school staff meet to discuss educational needs as part of the care planning process (DfE 2014a; Hayden 2005).

To summarise, while there is clearly some evidence that virtual schools are expected to consider the psychological factors underpinning educational attainment, and are well placed to 
intervene at multiple levels, we do not know enough about whether or how they are supporting these, or their perspectives on which types of provision are most successful.

\section{The present study}

The current study was therefore designed with the following research questions in mind: (1) How do the services provided to CLA, foster carers and schools address not only educational issues, but also the broader psychological factors that influence educational outcomes such as mental health and well-being, attachment, peer and family relationships, social and emotional understanding, and behaviour across the transition years? and (2) What types of provision are seen as most successful and what are the key factors that would improve service provision? VSHs or their nominated leads were invited to respond to an online survey to detail the services or training currently provided within their local authority, with an emphasis on the transition years. They were asked to identify the focus of each provision and to evaluate which services they perceived to be most effective, alongside barriers to successful service delivery.

\section{Method}

\section{Participants}

Details of our online survey were sent to 148 VSHs across nine regions in England: South East, South West, East Region, London, East Midlands, West Midlands, Yorks and Humber, North East and North West. Twenty-nine surveys were completed and returned online: 19 by the VSH, five by another member of staff at management level and five by a different member of the VS staff team. Regional response rates ranged from 0 to $28 \%$, with an overall response rate of $20 \%$.

\section{Survey description}

Participants were informed that the aim of the survey was to identify current provision within their local authority, with a particular focus on the support provided across the transition school years from primary to secondary school. Participants were asked to describe services provided directly by the VS as well as those provided within their local authority with other service providers.

Participants provided details of the number of staff employed by the VS and their roles and the numbers of CLA for whom they were currently responsible (from 0 to 200 up to > 1600), including the number currently in the transition school years from the last year of primary school (aged 10-11 years) to the second year of secondary school (aged 12-13 years). At the end of the survey, participants were invited to add further information about the structure and working partnerships of their VS.

The main focus of the online survey was on free text descriptions of services, support and training provided to three target groups: (1) CLA, (2) foster carers/families and (3) schools. A similar series of key questions was asked about each of these three targets, with small adjustments to the wording and selective display of relevant tick box options as appropriate to identify the focus and targeted recipients of each service and the professionals involved. In the final part of the survey, participants rated their satisfaction with service provision for each 
of the three target groups and identified strengths and areas for development. A full list of questions is included in the Appendix.

\section{Procedure}

The survey was developed in consultation with a planning group, including representatives from 12 virtual schools and organisations including the Nationwide Association of Fostering Providers (NAFP) and the Care Leavers' Association. This study was reviewed and approved by the appropriate institutional ethics committee.

VSHs were invited via email to complete the survey between November 2014 and January 2015. To facilitate dissemination of findings, participants were asked for consent to be listed as a provider of certain services and share their contact details. They were informed they would be given a personalised provision map, mapping their current provision in relation to the categories of service provision identified.

\section{Data analysis}

Free text responses were coded using NVivo10, a qualitative analysis software package that allows themes to be organised within a hierarchical structure. Responses were analysed using an inductive thematic analysis approach (Braun and Clarke 2006) and were grouped into broad themes based on content by one of the primary authors. Where multiple themes were mentioned in a single comment, all were credited. Initial themes and provision maps were shared with the core planning team of 12 virtual schools, and they were asked whether the themes identified from the coding of their services accurately reflected their provision as a check of coding validity. Descriptive and inferential statistics were computed for quantitative survey questions (scores on rating questions), but these are not the focus of this paper.

\section{Results}

Preliminary analysis of the VS responses showed great variability in the local context. The numbers of CLA that virtual schools were responsible for ranged from 0 to 200 to well above 1600; specifically, the number in the transition school years 6 to 8 (10- to 13-year olds) ranged from less than 20 to over 250. However, virtual schools responsible for similar numbers of CLA could vary greatly in terms of staffing numbers. The number of staff ranged from 2 to over 35 . The only role common to all was that of the statutory VSH and in 14 virtual schools, they were only part-time. In addition, the position of the VS within the local authority also varied (e.g. social care versus education).

\section{Service focus and provision}

We identified four key themes which will be considered in turn: enhanced learning opportunities, well-being and relationships, specific transition support and raising awareness. Labels following illustrative quotes indicate the contributions of different VSs (VS 1-29).

Enhanced learning opportunities Many services were focussed on providing enhanced opportunities for learning to raise educational attainment. 'Educational attainment' was the 
most frequently selected focus for service delivery and comments such as 'Our whole purpose is to improve the attainment of children looked-after and therefore their life chances' (VS 28) supported this theme. Direct work with CLA was frequently undertaken (see Table 1 for examples) and was identified in free text responses as a successful aspect of work by over a third of respondents, with the benefits of consistent, familiar support being emphasised across a diverse range of practice. As well as supporting current levels of attainment, several virtual schools were involved in providing broader structural and community support to young people to enhance longer term learning. Much of this work involved raising aspirations and awareness of careers and providing connections to further or higher education opportunities.

At the micro- and mesosystemic levels, virtual schools often worked strategically to increase learning opportunities and raise attainment through monitoring, intervention, partnership working (e.g. with social workers as well as school staff) and providing challenge. Monitoring data on educational attainment enabled virtual schools to prioritise children according to need and could inform the PEP cycle, the support provided as a result and the targeted spending of the Pupil Premium Plus budget. The sense of the VS as a force to not only support but challenge individual schools was captured by one respondent who wrote, 'We use PEP ... to drive up standards but also have good links with all our schools...Advice, guidance and challenge - this is the main aspect of our work.' (VS 28).

Table 1 Examples of direct provision to enhance learning opportunities

\begin{tabular}{|c|c|}
\hline \multicolumn{2}{|l|}{ One-to-one adult support } \\
\hline Tuition & $\begin{array}{l}\text { Identified by some virtual schools as being funded by the Pupil Premium Plus } \\
\text { budget; delivered by virtual school staff, private tutors or tutoring agencies; } \\
\text { could be responsive to need in terms of location and frequency. Provided } \\
\text { by } 7 \text { virtual schools }\end{array}$ \\
\hline Mentoring & $\begin{array}{l}\text { Often supports broader issues as well as educational attainment. Provided by } 9 \\
\text { virtual schools, with } 2 \text { providing specific transition learning mentors }\end{array}$ \\
\hline Caseworker & $\begin{array}{l}\text { Four virtual schools explicitly described individual caseworker support with a } \\
\text { focus on supporting education }\end{array}$ \\
\hline \multicolumn{2}{|l|}{ Educational interventions } \\
\hline In-placement resources & $\begin{array}{l}\text { Sending home of equipment and books to children looked-after in placement. } \\
\text { Provided by } 4 \text { virtual schools; } 2 \text { providing the evaluated provision 'Let- } \\
\text { terbox Club' - a parcel of books, maths activities, stationery sent home } \\
\text { monthly for } 6 \text { months }\end{array}$ \\
\hline Education workshops & $\begin{array}{l}\text { Delivered by } 2 \text { virtual schools for groups of pupils on aspects of the } \\
\text { curriculum requiring support, such as maths or writing, with } 1 \text { organising } \\
\text { the workshops for pupils to attend with carers }\end{array}$ \\
\hline \multirow{2}{*}{$\begin{array}{l}\text { Longer term education suppor } \\
\text { Careers advice, further and } \\
\text { higher education }\end{array}$} & \\
\hline & $\begin{array}{l}\text { Employment of careers advisors; post-16 advisors; education, employment } \\
\text { and training staff } \\
\text { Development of close links with work-related learning courses and local } \\
\text { education providers, including FE colleges and connexions } \\
\text { Employment and work experience initiatives and training and information } \\
\text { days on college applications and apprenticeships } \\
\text { Virtual college established in one local authority based in the local } \\
\text { university, offering a similar service to the virtual school but to young } \\
\text { people aged } 16 \text { plus. Close working partnership with the widening } \\
\text { participation teams at } 1 \text { local universities to provide bespoke and group } \\
\text { opportunities and raise aspirations } \\
\text { Annual 'Aim Higher' visits to give children looked-after the opportunity to } \\
\text { meet with current students who had been in care } \\
\text { Referred to or provided by } 11 \text { virtual schools }\end{array}$ \\
\hline
\end{tabular}


Well-being and relationships It was clear that virtual schools lead, fund or work collaboratively to support a great deal of work that also impacts on mental health and well-being, attachment, relationships, social and emotional understanding, behaviour and therefore the stability of home and school placements (see Table 2 for examples). Virtual schools rarely identified 'educational attainment' as the sole focus for the provision they were describing. The 'everyday' direct and strategic work that they undertook was frequently identified as supporting at least one and often several of the other focus areas, particularly social and emotional understanding, which was a strong theme across all three target groups. Much of the work within this theme was focussed on the micro- and mesosystemic systems around the child. Delivery of multi-agency training and whole school approaches to support well-being was a key feature of virtual schools' provision, with attachment theory having a strong influence on training delivered to foster carers and schools, and whole school interventions. Some distinct approaches were described, including one VS working on a pilot study run in partnership with a local university to develop 'Attachment Aware' schools (Rose 2014) and another that had embedded the Thrive approach ${ }^{1}$ to foster a more attachment friendly learning environment. Some had also developed a network of close working relationships with other services enabling access to priority assessments or interventions to support well-being when required. Seven virtual schools directly employed educational psychologists within their team, and this role was viewed positively. Working closely with multi-agency teams that included mental health provision was also seen as successful, but direct employment of staff with a clinical or mental health focus was less common. Very few virtual schools provided mental health support directly to children in the school setting, although one virtual school was running 'Zippy's Friends', a school mental health promotion program focussed on developing coping skills (Holen et al. 2012).

There were some distinct examples of virtual schools working with external providers to foster well-being, sometimes via the spending of the Pupil Premium Plus budget. One VS described working with third party providers to provide drama therapy, music, counselling services and a behavioural support service, stating that 'Managing Pupil Premium has helped us to respond to the need of schools and young people which is positive and has also helped us to be creative in our approaches to some interventions' (VS 20). There was less evidence of virtual school services providing microsystemic support at the peer group level. Reflecting this, supporting peer relationships did not come out as a strong focus area in the tick box focus choices either. However, some did provide small group or nurture-based peer support activities that, when detailed, were focussed on improving peer relationships and behaviour.

Specific transition support Specific support leading up to and during the transition period was frequently evident. The focus of most transition provision also went beyond a narrow view of educational attainment, with an emphasis on building resilience, self-esteem, confidence and peer relationships when approaching the move towards secondary school. In many cases, virtual schools were enhancing normal transition arrangements by directly working with the child and fostering more supportive relationships and understanding throughout the microsystems around them, including key staff in primary and secondary schools, carers and social workers. Examples of enhanced transition arrangements included accompanying CLA or carers on school visits to their new schools, nurture sessions and enhanced transition PEPs. A few virtual schools prioritised CLA for educational psychologist assessments to ensure year

\footnotetext{
${ }^{1}$ www.thriveapproach.co.uk
} 
Table 2 Examples of work supporting well-being and relationships

Support with attachment, trauma and behaviour

Mental health

Provision of extra-curricular support: focus identified as behaviour, social and emotional understanding or peer relationships
- Attachment training for schools, provided by 11 virtual schools, in 2 cases with support from university or national specialist agency

- School self-assessment frameworks

$\circ$ VS staff trained in Thrive approach, supporting school staff to become Thrive practitioners

o 'Space to Reflect' in collaboration with external provider supporting professionals working with CLA with challenging behaviour

- Foster carer support using relationship-based play drawing on 'Theraplay' principles

- Conferences for foster carers and/or school staff (4 VS)

- Training for foster carers where the focus identified went beyond educational attainment (18 virtual schools)

○ Zippy's Friends: a 24-week positive mental health after school provision

- Multi-agency 'CLA development days' on mental health, emotional well-being and attachment

- Support for foster carers provided by VS employed educational psychologist and mental health worker

- Virtual school run nurture group - activities including gardening, cooking and sport

- One-to-one or small group support from VS inclusion officers - activities such as fishing, gardening, pottery, museum visits

- Positive Chances scheme delivered in partnership with a community trust-outdoor and adventurous activities, one-to-one support, family days, emotional health groups (1 VS)

$\circ$ See previous sections

7 support would be appropriate, and one VS often accessed their local authority's dedicated quick response Child and Adolescent Mental Health Service for CLA during transition.

The examples shown in Table 3 demonstrate that support could also be individualised; mentors and caseworkers were sometimes employed by the VS to provide a stable, familiar and consistent point of contact during this period of change. Where transition mentors were employed, they could work with the pupil across transition and beyond in some cases, to build relationships and facilitate communication. Specific transition support during school holidays was a distinct form of support provided by a few virtual schools, which again had a broader emphasis on the socio-emotional preparation for a new school, and was one form of provision in which the peer microsystem was supported by VS practice.

Raising awareness A key element to the virtual schools' work was the raising of awareness of the needs of CLA so that they could be better supported within educational settings. The specialist knowledge and expertise of VS staff were viewed as successful contributing factors within this theme. At the microsystemic level, training and close working relationships with foster carers, social workers and other professionals such as educational psychologists were very evident. In two local authorities, specific training for teachers and social workers new into the profession was also detailed. 
Table 3 Examples of transition support

\begin{tabular}{|c|c|}
\hline \multirow[t]{6}{*}{$\begin{array}{l}\text { Enhanced transition } \\
\text { arrangements and support }\end{array}$} & $\begin{array}{l}\text { - Accompanying children looked-after or carers on school visits to their new } \\
\text { secondary schools }\end{array}$ \\
\hline & - Organising extra school visits \\
\hline & - Nurture sessions at the secondary school \\
\hline & ○ Enhanced transition PEPs \\
\hline & $\begin{array}{l}\text { Priority educational psychologist assessments to ensure year } 7 \text { support } \\
\text { would be appropriate if needed }\end{array}$ \\
\hline & - Accessing the local authority's dedicated quick response Child and \\
\hline \multirow[t]{2}{*}{ One-to-one support } & $\begin{array}{l}\text { Adolescent Mental Health (CAMHS) service for CLA (1 VS) } \\
\text { o Transition learning mentors - employed by } 2 \text { virtual schools }\end{array}$ \\
\hline & $\begin{array}{l}\text { Intensive use of caseworkers, learning mentors and teaching assistants } \\
\text { during the transition period }\end{array}$ \\
\hline \multirow[t]{5}{*}{ School holiday transition support } & Four different virtual schools' provisions: \\
\hline & ○ Week long summer school \\
\hline & - Residential transition camp for year 6 children \\
\hline & $\begin{array}{l}\text { O Summer holiday workshops-including trips, workshops on making } \\
\text { friends and study skills }\end{array}$ \\
\hline & - Summer trips and outdoor activities focussed on transitioning pupils \\
\hline
\end{tabular}

However, it was the importance of effective relationships with key staff in schools, particularly DTs, which came across most strongly. Twenty-one virtual schools detailed at least one provision specifically provided for DTs, including training, forums, conferences and network meetings. In England, the running of each school is overseen by a voluntary governing body, and a similar level of support was provided for those governors who had designated responsibility for monitoring the provision for CLA. Where detailed, the focus of training and support for DTs and governors included their statutory responsibilities as well as the broader issues affecting CLA, such as the effects of broken attachments and trauma. Raising awareness of educational issues and statutory responsibilities was also facilitated through support to schools' senior leadership teams and attendance at headteachers' network meetings.

It was within this theme that the exosystemic influence of the virtual school was apparent. Most virtual schools reported close working links with other departments within education such as the Education Welfare, Behaviour and Attendance Services, Special Educational Needs and Disability and Learning Support teams, Inclusion and Admissions. The new statutory role of the VSH was also viewed as a facilitator in helping to raise awareness more broadly: 'It has added leverage to our process and has led to an increase in the number of professional partners taking note of our strategies, messages and recommendations' (VS 10), helping to overcome the fact that the needs of CLA in education are still often seen as a 'minority issue' (VS 1).

\section{Self-evaluations of provision}

As noted earlier, respondents were asked whether they felt they provided a good level of support to children looked-after, foster carers and schools around the secondary school transition. Our analyses of the responses indicated that the support provided to foster carers was viewed as being significantly less effective than the support provided to CLA, with ratings of support to schools in between the two. 
Reflecting this, participants identified a need to extend the work carried out with those in the microsystems around the child, particularly school staff, foster carers and other professionals. One VS stated, 'We would like to see those closest to the children be supported and to be given time to do some of this work' (VS 29). Further development of training opportunities and direct support to these key adults was one identified approach, with a focus on raised awareness of educational issues, including the impact of being in care and attachment issues on learning and transition. Specialist direct work with young people was viewed as successful and the need to extend or establish individualised support such as direct teaching and mentoring, especially around transitions, was another clear subtheme. This was reflected in comments such as 'Would like to have sufficient staff to have a mentor to support the transition of every young person transferring', 'Routine support for all transition students', 'Specific 1:1 support for CLA in transition where needed' and the ability to 'offer Y6 to Y7 (mentor) sessions to a wider audience.'

At the mesosystemic level, the need to work together with both foster carers and schools to develop a joined-up approach to transition was highlighted. At an exosystemic level, the need to develop or extend mental health provision or educational psychology services within the virtual school, particularly to benefit from this kind of expertise at transition, was also an identified gap in provision in some virtual schools. Effective partnership and multi-agency working were viewed as key to facilitating high-quality service delivery.

\section{Discussion}

This survey has revealed that although enhancing educational opportunities and supporting transition were the strongest themes in our analyses, the work of virtual schools does address many of the broader psychological factors known to affect educational attainment. Support for social and emotional understanding featured strongly, along with a clear focus on deepening the understanding of attachment and trauma in the work undertaken with schools and foster families. Specific support for transition, including mentoring and casework, was evident in the practice of several virtual schools. Participants pointed to extending support at the microsystemic level, to both carers and schools, and interprofessional working as key directions for improving services.

Although this study identified four clear themes across virtual school provision, they are closely interrelated. For example, the positive associations between educational attainment, the strongest theme and well-being are well established (Public Health England 2014). Higher educational attainment is strongly associated with higher life satisfaction among young people and higher well-being in adults (Chanfrreau et al. 2013), while in turn health, well-being and social and emotional competency contribute towards academic attainment and engagement (Gutman and Vorhaus 2012). Thus, even the direct interventions that have a clear educational focus, such as individual tutoring, are likely to have longer term benefits for psychological adjustment. Supporting mental health at transition is also beneficial for academic attainment, since depressive symptoms, lower school liking and conduct problems in general samples of children at the start of year 7 have been found to predict lower attainment across time (Riglin et al. 2013). Higher school concerns across transition are also associated with reduced enjoyment of school, lower trust of teachers and anxiety in general population studies (Rice et al. 2011), while in contrast, enhanced support in the secondary school and bridging links between school contexts are strongly associated with a more successful transition and settled 
time at secondary school (Evangelou et al. 2008). Support across multiple ecological systems including planning and information sharing among key stakeholders and individualised, holistic support have also been identified as important factors associated with positive transitions for CLA (Brewin and Statham 2011). Indeed, support from external resources may be particularly important for resilient outcomes in young people who have experienced trauma and maltreatment (e.g. Ungar 2013).

This type of multisystemic practice was evident in much of the work of virtual schools, reflecting the importance of placing relationships and emotional well-being at the heart of whole system approaches for CLA (Bazalgette et al. 2015a; Selwyn and Briheim-Crookall 2017). Aspects of virtual school provision across all four themes can be conceptualised as fostering resilience by enhancing the micro- and mesosystems around each child, from enhanced individual transition support to the embedding of systemic practices such as Thrive or Attachment Aware schools. The fact that all these approaches emphasise positive relationships, which are viewed by many as the most critical protective factor for resilience in young people, is important (e.g. Luthar 2006). Positive relationships with others have been identified as the key factor to successful transitions (Coffey 2013), and relationships have been described as the 'golden thread' in children's lives that should inform all work with CLA (Care Inquiry 2013). Mentoring and caseworker support, for example, involves the building of meaningful and sustained relationships which were clearly valued by the virtual schools and were often identified as particularly relevant during periods of transition. This is encouraging since the importance of 'natural' mentors such as teachers, carers and other adults within the child looked-after's every day environment has been well documented in terms of improving educational achievement (Martin and Jackson 2002) and psychological outcomes (Ahrens et al. 2008; Gilligan 1999; Greeson and Bowen 2008).

Attachment-based approaches similarly place an understanding of behaviour within relational contexts (Rose et al. 2016), and by working holistically with the microsystems around the child can be viewed as a form of early intervention that may prevent the need for specialist interventions later. Making environments more supportive through a raised awareness of the impact of early attachment disturbances and trauma was a distinct aspect of services to foster carers and schools. Delivering focussed attachment awareness training, often in collaboration with other professionals, was the most common way in which this issue was addressed. However, a few virtual schools were working with private agencies or local universities, to develop Attachment Aware (Rose 2014) or 'attachment friendly' schools (Sunderland University Training n.d.). These encompass whole school approaches to support emotional wellbeing, alongside targeted and specialist support where needed (Rose et al. 2014), and there are promising indications that such approaches support behaviour, attendance and attainment (Parker et al. 2016). These initiatives indicate a commitment to work collaboratively to both develop and implement evidence-based practice across schools in their localities, and is one way in which VS practice is supporting the implementation of best practice guidelines on attachment (NICE 2015). This is important, especially given concerns that many teachers currently feel ill-prepared to be the 'front line' staff dealing with issues such as mental health (Rothi et al. 2008).

Moreover, social and emotional understanding was the most frequently identified focus of service delivery after educational attainment and transition. Placing social and emotional understanding at the heart of education can benefit educational outcomes and mental health and well-being for all pupils if implemented effectively and with consideration of how specific interventions relate to the wider school systems and climate (Banerjee et al. 2016; McLaughlin 
2015). There is a growing evidence base that children who have experienced maltreatment have distinct difficulties with social and emotional understanding (Luke and Banerjee 2013) and that deficits in advanced aspects of social understanding can persist into adulthood for individuals who have experienced maltreatment as children (Germine et al. 2015), so the fact that virtual schools frequently identify it as a focus area for their services and training to children across the transition years is encouraging.

One possibility is that this work can be fruitfully integrated with strategies involving CLA's peer groups; although explicit references to a focus on peer relationships were infrequent, some virtual schools did identify relevant peer group contexts for interventions such as small group activities or nurture groups. Given the strong connection between peer attachments, school connectedness and increased prosocial behaviours (Oldfield et al. 2016; Wentzel 1998), which in turn are linked to better academic achievement (Miles and Stipek 2006; Wentzel 1993), this may be a particularly important aspect of creating a supportive environment for CLA, especially across transition periods. This is often a key time when new peer relationships are established, and difficulties with social skills and making friends have been identified as challenging areas for CLA at transition (Brewin and Statham 2011). Where the peer context is positive before transition, this can predict aspects of later adjustment post-transition such as self-esteem, school involvement and academic achievement (Kingery et al. 2011).

Given the acknowledged importance of interprofessional working for achieving positive outcomes (NICE 2010, 2015), it is encouraging that this was strongly evident in VS practice at the exosystemic level. Without exception, the work of all virtual schools was carried out within the context of close working relationships with other services and professionals, particularly those working within education and social care, but also health professionals within Child and Adolescent Mental Health Services (CAMHS) or specialist interdisciplinary services in some local authorities. The degree to which virtual schools worked with other professionals was linked to the focus area of the provision. For example, where mental health was identified as a focus of service delivery or training, it was generally supported through working relationships with other professionals, sometimes employed directly by the VS, such as a primary mental health worker. A positive view of educational psychologists on the teams, as well as an expressed desire by some to extend educational psychology and mental health provision, highlights the fact that some virtual schools view this as an aspect of work that can be developed given the right funding, professional support and working relationships.

The frequency with which virtual schools provided training, forums and resources specifically to support designated teachers and governors provides evidence for the crucial importance of these interprofessional working relationships. The significant role of schools and teachers in terms of supporting resilient outcomes has been established in social work and educational psychology literature, and schools have been identified as providing the daily context within which young people can form positive relationships with caring and competent people (e.g. Dent et al. 2003; Gilligan 1998). Such relationships have the potential to promote positive development, and support the development of self-regulation, self-esteem and self-efficacy, emphasising the important role schools have to play when resilience is viewed as not only reducing risk but also increasing resources and fostering protective systems (Masten 2001, 2007). From the findings of this survey, the designated teacher appears to play a crucial role in supporting resilient outcomes as the key link between the VS and the everyday educational environments of most CLA. This role was established to drive forward the commitment to increasing the educational attainment of children looked-after (Department for Education and Employment (DfEE) and Department of Health (DoH) 2000) and placed on a statutory footing following the Children and Young Person's 
Act (2008). Their role in supporting whole school approaches to understanding issues such as attachment and having specialist training in attachment difficulties and mental health problems has been highlighted (NICE 2015, p. 12-13) and so it is encouraging to see that the practices of VS are supporting this.

\section{Limitations and directions for further research}

Although this study represents the largest survey of VS provision to date, we acknowledge it is still based on the responses of 29 virtual schools. This represents approximately $20 \%$ of the total number across English local authorities, which is lower than the average response rate to organisation surveys (Baruch and Holtom 2008), and low response rates can affect the credibility of a survey among stakeholders (Rogelberg and Stanton 2007). Given the variety of provision, working roles and service structures evident across these virtual schools, we cannot necessarily view them as representative of provision across the country, since in general better response rates suggest a higher probability that the sample is representative (Baruch and Holtom 2008). Indeed, some VSHs may have chosen not to respond because they felt that their provision was limited or not exemplary of good practice, or that others were unable to do so due to more limited staff or time resources. However, the diversity evident within the achieved sample has helped to highlight the breadth of provision across a varied sample of virtual schools of different sizes and geographical locations. As such, it provides a valuable snapshot of evolving provision in the context of local priorities, that broadly reflects the current priorities of the National Association of Virtual School Headteachers.

Our analyses also revealed that while most virtual schools felt they provided a good level of support to schools and CLA across the transition years, they were less satisfied with the support they were currently providing to foster families. The importance of the quality of the 'ordinary care' provided by the foster carer placement and the impact of interventions focussed on those around the child to supporting well-being and stable outcomes has been emphasised (Luke et al. 2014). Further identification of barriers to supporting foster carers, specifically in the domain of education, would be valuable, including ways to improve a 'joined-up' approach to transition between schools and placement.

Evaluating the value of individual transition support as well as developing a focussed understanding of the barriers and facilitators to such provision would be timely, given that several virtual schools expressed a desire to develop or extend this, including mentoring. Within the school context, there is also a lack of research into DTs and their working relationship with VSHs. One study, focussed on joint working to support students at the end of secondary school, found that provision and experience of DTs varied greatly within a small sample (Driscoll 2013). Therefore, further research into how best to consolidate and ensure consistency and best practice in these relationships, especially as children transition between schools, is required.

Finally, we acknowledge that this study analyses one country's strategy of the role of a statutory virtual school head to support the educational under-attainment of children lookedafter. However, comparable educational under-attainment has been identified as an issue in many other countries as well (Dill et al. 2012), as have issues of mental health and well-being, including in other areas of the UK such as Northern Ireland (McSherry et al. 2015) and Wales (Bazalgette et al. 2015b). It would be of interest to compare the role of the virtual school head and the approaches taken by virtual schools identified in this paper with other models of support in different countries and other parts of the UK. 


\section{Conclusions}

Virtual schools are working proactively at multiple levels around the child to address the factors affecting the educational outcomes of children looked-after. Virtual schools provide direct support, while also supporting resilient outcomes through close interprofessional working relationships and the development of supportive environments. Much of their work goes beyond a narrow focus on raising attainment, to support many of the underlying psychological issues such as attachment, social and emotional understanding, relationships and well-being. Further research into how they support well-being and education is needed, alongside rigorous research into what interventions work best to guide VSHs as they make decisions about how best to support the children in their care.

Acknowledgements Advice and support with design has been provided by Mary John at the School of Psychology, University of Surrey; Nikki Luke at the Rees Centre for Research in Fostering and Education, University of Oxford; and a steering group including foster carers, care leavers and representatives from virtual schools.

Funding This research has been jointly funded through a $\mathrm{PhD}$ studentship by the University of Sussex and Sussex Partnership NHS Foundation Trust.

\section{Appendix}

\section{Method}

Following each free text description of a service, participants were asked to complete tick box options in response to the following questions:

- What is the focus of the service? [Tick all that apply: Mental health, Behaviour Support, Social and Emotional Understanding, Educational Attainment, Attachment, Peer Relationships, Family Relationships, Placement Stability, Other]

- Who is the service or training provided for? [Tick all that apply: Child looked-after, Looked-after sibling groups, Child looked-after and peer group, Foster carers only, Whole family, Senior Management, SENCOs/INCOs, Governors, Class Teachers, Teaching Assistants, Other]

- At what level is the service or training provided? [Tick all that apply: Individual Families, Groups of Families, Individuals, Groups, Classes, Whole School, Clusters of Schools, Across the Local Authority, Other]

- Can the service or training be tailored to the needs of individuals or families/an individual child or group of children? [Yes, No]

- Was this service or training developed in collaboration with children looked-after and/or their foster families? [Yes, No]

- Who provides this service? [Tick all that apply: Virtual School directly, Other Service Providers within the Local Authority, Service providers from another Local Authority, Private Agency]. Participants then named the professionals involved with each provision.

In the final part of the survey, participants rated their agreement with three statements: 'We provide a good level of support to children looked-after / foster families / schools around transition' on a five-point scale from 'Strongly disagree' (1) to 'Strongly agree' (5). 
Free text responses were invited in response to the questions: 'Which of your services or training do you feel are most effective at meeting the needs of children looked-after during transition?'; 'What services, training or interventions would you like to offer that you are not currently able to?'; 'What are the current obstacles that prevent you from developing or implementing the services or training that you would like to provide?'; 'What are the factors that facilitate development and implementation of training and services?'; and 'Which types of services, training or interventions would you like more information about?'

Open Access This article is distributed under the terms of the Creative Commons Attribution 4.0 International License (http://creativecommons.org/licenses/by/4.0/), which permits unrestricted use, distribution, and reproduction in any medium, provided you give appropriate credit to the original author(s) and the source, provide a link to the Creative Commons license, and indicate if changes were made.

\section{References}

Ahrens, K. R., DuBois, D. L., Richardson, L. P., Fan, M. Y., \& Lozano, P. (2008). Youth in foster care with adult mentors during adolescence have improved adult outcomes. Pediatrics, 121(2), 246-252.

Alink, L. R. A., Cicchetti, D., Kim, J., \& Rogosch, F. A. (2012). Longitudinal associations among child maltreatment, social functioning, and cortisol regulation. Developmental Psychology, 48(1), 224-236.

Anderson, L. W., Jacobs, J., Schramm, S., \& Splittgerber, F. (2000). School transitions: beginning of the end or a new beginning? International Journal of Educational Research, 33(4), 325-339.

Banerjee, R., Weare, K., \& Farr, W. (2014). Working with "social and emotional aspects of learning" (SEAL): associations with school ethos, pupil social experiences, attendance, and attainment. British Educational Research Journal, 40(4), 718-742.

Banerjee, R., Mclaughlin, C., Cotney, J., Roberts, L., \& Peereboom, C. (2016). Promoting emotional health, well-being, and resilience in primary schools. Cardiff: Public Policy Institute for Wales.

Baruch, Y., \& Holtom, B. C. (2008). Survey response rate levels and trends in organizational research. Human Relations, 61(8), 1139-1160.

Bazalgette, L., Rahilly, T., \& Trevelyan, G. (2015a). Achieving emotional wellbeing for looked after children: a whole system approach. London: NSPCC.

Bazalgette, L., Rahilly, T., \& Trevelyan, G. (2015b). Achieving emotional wellbeing for looked after children: a whole system approach. NSPCC Cymru/Wales briefing. London: NSPCC Retrieved from https://www. nspcc.org.uk/globalassets/documents/research-reports/achieving-emotional-wellbeing-for-looked-afterchildren-cymru-wales-briefing.pdf.

Bergin, C., \& Bergin, D. (2009). Attachment in the classroom. Educational Psychology Review, 21(2), 141-170.

Berridge, D. (2009). Looked after and learning: an evaluation of the virtual school head pilot. London: Department for Education.

Berridge, D. (2012). Educating young people in care: what have we learned? Children and Youth Services Review, 34(6), 1171-1175.

Bombèr, L. (2007). Inside I'm hurting; practical strategies for supporting children with attachment difficulties in schools. London: Worth Publishing.

Bombèr, L. (2011). What about me? Inclusive strategies to support pupils with attachment difficulties make it through the school day. London: Worth Publishing.

Braun, V., \& Clarke, V. (2006). Using thematic analysis in psychology. Qualitative Research in Psychology, 3(2), 77-101.

Brewin, M., \& Statham, J. (2011). Supporting the transition from primary school to secondary school for children who are looked after. Educational Psychology in Practice, 27(4), 365-381.

Bronfenbrenner, U. (1979). The ecology of human development: experiments by nature and design. Cambridge: Harvard University Press.

Bronfenbrenner, U., \& Morris, P. (2006). The bioecological model of human development. Handbook of child psychology, theoretical models of human development, 793-828.

Care Inquiry. (2013). Making not breaking: building relationships for our most vulnerable children. Retrieved from http://thecareinquiry.files. wordpress.com/2013/04/care-inquiry-full-report-april-2013.pdf.

Chanfrreau, J., Lloyd, C., Byron, C., Roberts, R., Craig, D., De Foe, D., \& McManus, S. (2013). Predicting wellbeing. Prepared by NatCen Social Research for the Department of Health. Retrieved from: www.natcen. ac.uk/media/205352/predictors-of-wellbeing.pdf

Cicchetti, D., Rogosch, F. A., \& Toth, S. L. (2006). Fostering secure attachment in infants in maltreating families through preventive interventions. Development and Psychopathology, 18(3), 623-649. 
Coffey, A. (2013). Relationships: the key to successful transition from primary to secondary school? Improving Schools, 16(3), 261-271.

Cyr, C., Euser, E. M., Bakermans-Kranenburg, M. J., \& Van Ijzendoorn, M. H. (2010). Attachment security and disorganization in maltreating and high-risk families: a series of meta-analyses. Development and Psychopathology, 22(1), 87-108.

Daly, F., \& Gilligan, R. (2005). Lives in foster care - the educational and social support experiences of young people aged 13-14 years in long-term foster care. Dublin: Children's Research Centre, Trinity College.

Daniel, B., Wassell, S., \& Gilligan, R. (1999). "It's just common sense isn't it?": exploring ways of putting the theory of resilience into action. Adoption \& Fostering, 23(3), 6-15.

Darwish, D., Esquivel, G. B., Houtz, J. C., \& Alfonso, V. C. (2001). Play and social skills in maltreated and nonmaltreated preschoolers during peer interactions. Child Abuse and Neglect, 25(1), 13-31.

Dent, R. J., \& Cameron, R. J. S. (2003). Developing resilience in children who are in public care: the educational psychology perspective. Educational Psychology in Practice, 19(1), 3-19.

Department for Education. (2014a). Promoting the education of looked-after children. Statutory guidance for local authorities. London: Department for Education Retrieved from: https://www.gov. uk/government/uploads/system/uploads/attachment_data/file/335964/Promoting_the_educational achievement_of_looked_after_children_Final_23-...pdf.

Department for Education. (2014b). Pupil premium: virtual school heads' responsibilities. London: Department for Education Retrieved from: https:/www.gov.uk/guidance/pupil-premium-virtual-school-heads-responsibilities.

Department for Education. (2017a). Children looked after in England (including adoption) year ending 31 March 2017: SFR50/2017. London: Department for Education Retrieved from https://www.gov. uk/government/uploads/system/uploads/attachment_data/file/664995/SFR50_2017-Children_looked_after_in England.pdf.

Department for Education. (2016). Special educational needs in England: January 2016 SFR29/ 2016. London: Department for Education Retrieved from https://www.gov.uk/government/uploads/system/uploads/attachment data/file/539158/SFR29 2016_Main_Text.pdf.

Department for Education. (2017b). Outcomes for children looked-after by LAs: 31 March 2016: SFR12/2017. London: Department for Education Retrieved from https://www.gov. uk/government/uploads/system/uploads/attachment_data/file/602087/SFR12_2017_Text.pdf.

Department for Education and Employment (DfEE) and Department of Health (DoH). (2000). Guidance on the education of children and young people in public care. London: DfEE.

Drake, K., Belsky, J., \& Fearon, R. M. P. (2014). From early attachment to engagement with learning in school: the role of self-regulation and persistence. Developmental Psychology, 50(5), 1350-1361.

Dill, K., Flynn, R. J., Hollingshead, M., \& Fernandes, A. (2012). Improving the educational achievement of young people in out-of-home care. Children and Youth Services Review, 34(6), 1081-1083.

Driscoll, J. (2013). Supporting the educational transitions of looked after children at key stage 4: the role of virtual schools and designated teachers. Journal of Children's Services, 8(2), 110-122.

Egeland, B., Yates, T., Appleyard, K., \& Van Dulmen, M. (2002). The long-term consequences of maltreatment in the early years: a developmental pathway model to antisocial behavior. Children's Services: Social Policy, Research, and Practice, 5(4), 249-260.

"Emotional Health and Well-being" (n.d.) Retrieved from http://www.navsh.org.uk/informationfor/schools\#emotional

Evangelou, M., Taggart, B., Sylva, K., Melhuish, E., Sammons, P., \& Siraj-Blatchford, I. (2008). What makes a successful transition from primary to secondary school? Findings from the effective pre-school, primary and secondary education 3-14 (EPPSE) project (research report DCSF-RR019). Nottingham: DCSF.

Fearon, R. M. P., Bakermans-Kranenburg, M. J., van IJzendoorn, M. H., Lapsley, A. M., \& Roisman, G. I. (2010). The significance of insecure attachment and disorganization in the development of children's externalising behaviour: a meta-analytic study. Child Development, 81(2), 435-456.

Fisher, P. A. (2015). Review: adoption, fostering, and the needs of looked-after and adopted children. Child and Adolescent Mental Health, 20(1), 5-12.

Fletcher-Campbell, F. (1998). Progress or procrastination? The education of young people who are looked after. Children \& Society, 12(1), 3-11.

Ford, T., Vostanis, P., Meltzer, H., \& Goodman, R. (2007). Psychiatric disorder among British children looked after by local authorities: comparison with children living in private households. The British Journal of Psychiatry: the Journal of Mental Science, 190(04), 319-325.

Geddes, H. (2006). Attachment in the classroom: the links between children's early experience, emotional wellbeing and performance in schools. London: Worth Publishing.

Germine, L., Dunn, E. C., McLaughlin, K. A., \& Smoller, J. W. (2015). Childhood adversity is associated with adult theory of mind and social affiliation, but not face processing. PLoS One, 10(6), e0129612.

Gilligan, R. (1998). The importance of schools and teachers in child welfare. Child \& Family Social Work, 3(1), 13-25. 
Gilligan, R. (1999). Enhancing the resilience of children and young people in public care by mentoring their talents and interests. Child \& Family Social Work, 4(3), 187-196.

Goddard, J. (2000). The education of looked after children. Child and Family Social Work, 5(1), 79-86.

Greeson, J. K. P., \& Bowen, N. K. (2008). "She holds my hand"- the experiences of foster youth with their natural mentors. Children and Youth Services Review, 30(10), 1178-1188.

Gutman, L., \& Vorhaus, J. (2012). The impact of pupil behaviour and wellbeing on educational outcomes. London: DfE.

Harker, R. M., Dobel-Ober, D., Berridge, D., \& Sinclair, R. (2004). Taking care of education: an evaluation of the education of looked after children. London: National Children's Bureau.

Hart, A., Stubbs, C., Plexousakis, S., Georgiadi, M., \& Kourkoutas, E. (2015). Aspirations of vulnerable young people in foster care, STYLE working papers no WP 9.3. Brighton: Centre for Research on Management and Employment Retrieved from: http://www.style-research.eu/wordpress/wp-content/uploads/2015/03/D_9_3_ Aspirations_of_vulnerable_youth_in_foster_care_FINAL.docx.

Hayden, C. (2005). More than a piece of paper? Personal education plans and "looked after" children in England. Child and Family Social Work, 10(4), 343-352.

Holen, S., Waaktaar, T., Lervåg, A., \& Ystgaard, M. (2012). The effectiveness of a universal school-based programme on coping and mental health: a randomised, controlled study of Zippy's Friends. Educational Psychology, 32(5), 657-677.

Holland, S., Faulkner, A., \& Perez-del-Aguila, R. (2005). Promoting stability and continuity of care for looked after children: a survey and critical review. Child \& Family Social Work, 10(1), 29-41.

Howe, D., \& Fearnley, S. (2003). Disorders of attachment in adopted and fostered children: recognition and treatment. Clinical Child Psychology and Psychiatry, 8(3), 369-387.

Jackson, S. (1988). Residential care and education. Children \& Society, 2(4), 335-350.

Jackson, S. (1989). The education of children in care. In B. Kahan (Ed.), Child care: research, policy and practice. London: Hodder and Stoughton.

Jackson, S. (1994). Educating children in residential and foster care. Oxford Review of Education, 20(3), $267-279$.

Jackson, S., Ajayi, S., \& Quigley, M. (2005). Going to university from care. London: Institute of Education, University of London.

Jackson, S., \& Sachdev, D. (2001). Better education, better futures: research, practice and the views of young people in public care. Ilford: Barnardos.

Kingery, J., Erdley, C., \& Marshall, K. (2011). Peer acceptance and friendship as predictors of early adolescents' adjustment across the middle school transition. Merrill-Palmer Quarterly, 57(3), 215-243.

Luke, N., \& Banerjee, R. (2011). Maltreated children's social understanding and empathy: a preliminary exploration of foster carers' perspectives. Journal of Child and Family Studies, 21(2), 237-246.

Luke, N., \& Banerjee, R. (2013). Differentiated associations between childhood maltreatment experiences and social understanding: a meta-analysis and systematic review. Developmental Review, 33(1), 1-28.

Luke, N., Sinclair, I., Woolgar, M., \& Sebba, J. (2014). What works in preventing and treating poor mental health in looked after children. London: NSPCC.

Luthar, S. S. (2006). Resilience in development: a synthesis of research across five decades. In D. Cicchetti \& D. J. Cohen (Eds.), Developmental psychopathology: risk, disorder and adaptation (pp. 739-795). Hoboken: Wiley.

Madigan, S., Atkinson, L., Laurin, K., \& Benoit, D. (2012). Attachment and internalizing behavior in early childhood: a meta-analysis. Developmental Psychology, 49(4), 672-689.

Martin, P. Y., \& Jackson, S. (2002). Educational success for children in public care: advice from a group of high achievers. Child \& Family Social Work., 7(2), 121-130.

Masten, A. S. (2001). Ordinary magic: resilience processes in development. American Psychologist, 56(3), $227-238$.

Masten, A. S. (2007). Resilience in developing systems: progress and promise as the fourth wave rises. Development and Psychopathology, 19(03), 921-930.

Matas, L., Arend, R.-A., \& Sroufe, L. A. (1978). Continuity of adaptation in the second year: the relationship between quality of attachment and later competence. Child Development, 49(3), 547-556.

McLaughlin, C. (Ed.). (2015). The connected school: a design for well-being-supporting children and young people in schools to flourish, thrive and achieve. London: Pearson Retrieved from: http://cdn.basw.co. uk/upload/basw 111244-8.pdf.

McSherry, D., Fargas Malet, M., McLaughlin, K., Adams, C., O’Neill, N., Cole, J., \& Walsh, C. (2015). Mind your health: the physical and mental health of looked after children and young people in Northern Ireland. Belfast: Queens University Belfast.

Meltzer, H., Corbin, T., Gatward, R., Goodman, R., \& Ford, T. (2003). The mental health of young people looked-after by local authorities in England. Office for National Statistics. London: HMSO.

Miles, S., \& Stipek, D. (2006). Contemporaneous and longitudinal associations between social behavior and literacy achievement in a sample of low-income elementary school children. Child Development, 77(1), 103-117. 
Morgan, S. (1999). Care about education: a joint training curriculum for supporting children in public care. London: National Children's Bureau.

National Institute for Health and Clinical Excellence (NICE). (2008). Social and emotional wellbeing in primary education. NICE Public Health Guidance, (12). London: NICE Retrieved from: http:/guidance.nice.org.uk/PH12

NICE (2009). Social and emotional wellbeing in secondary education. NICE Public Health Guidance, (20), 47. London: NICE Retrieved from: http://guidance.nice.org.uk/PH20

NICE (2010). Looked after children and young people NICE Public Health Guidance, (28). London: NICE. Retrieved from: https://www.nice.org.uk/guidance/PH28

NICE (2015). Children's attachment: attachment in children and young people who are adopted from care, in care or at high risk of going into care. NICE Guidelines, (26). (London, UK). Retrieved from: https://www.nice. org.uk/guidance/ng26

Office for Standards in Education (Ofsted). (2016). Ofsted social care annual report 2016. London: Ofsted.

O'Higgins, A., Sebba, J., \& Luke, N. (2015). What is the relationship between being in care and the educational outcomes of children? An international systematic review. Oxford: Rees Centre for Research in Fostering and Education, University of Oxford.

Oldfield, J., Humphrey, N., \& Hebron, J. (2016). The role of parental and peer attachment relationships and school connectedness in predicting adolescent mental health outcomes. Child and Adolescent Mental Health, 1, 21-29.

Osterling, K. L., \& Hines, A. M. (2006). Mentoring adolescent foster youth: promoting resilience during developmental transitions. Child and Family Social Work, 11(3), 242-253.

Parker, J. G., \& Herrera, C. (1996). Interpersonal processes in friendship: a comparison of abused and nonabused children's experiences. Developmental Psychology, 32(6), 1025-1038.

Parker, R., Rose, J., \& Gilbert, L. (2016). Attachment aware schools: an alternative to behaviourism in supporting children's behaviour? In H. Lees \& N. Noddings (Eds.), The Palgrave international handbook of alternative education. London: Palgrave MacMillan.

Public Health England. (2014). The link between pupil health and wellbeing and attainment: a briefing for head teachers, governors and staff in education settings. London: Public Health England.

Rees, A., \& The National Virtual School Network (2015). The virtual school handbook. Oxford: Rees Centre for Research in Fostering and Education, University of Oxford. Retrieved from: http://reescentre.education.ox. ac.uk/wordpress/wp-content/uploads/2015/06/2015-06-08-Virtual-School-Handbook.pdf

Rice, F., Frederickson, N., \& Seymour, J. (2011). Assessing pupil concerns about transition to secondary school. British Journal of Educational Psychology, 81(2), 244-263.

Riglin, L., Frederickson, N., Shelton, K. H., \& Rice, F. (2013). A longitudinal study of psychological functioning and academic attainment at the transition to secondary school. Journal of Adolescence, 36(3), 507-517.

Rogelberg, S., \& Stanton, J. (2007). Understanding and dealing with organizational survey non-response. Organizational Research Methods, 10(2), 195-209.

Rose, J. (2014). An 'attachment aware' approach benefits all. Primary Teacher Update, 2014(36), 38-39.

Rose, J., Gilbert, L., Gorman, M., \& Parker, R. (2014). An introduction to attachment and the implications for learning and behaviour. Nottingham: NCTL.

Rose, J., McGuire-Snieckus, R., \& Gilbert, L. (2016) Attachment aware schools: a pilot study. Paper presented at the American Education Research Association Conference, Washington DC, April 2016.

Rothì, D. M., Leavey, G., \& Best, R. (2008). On the front-line: teachers as active observers of pupils' mental health. Teaching and Teacher Education, 24(5), 1217-1231.

Rutter, M. (2007). Resilience, competence, and coping. Child Abuse \& Neglect, 31(3), 205-209.

Rutter, M. (2012). Resilience as a dynamic concept. Development and Psychopathology, 24(2012), 335-344.

Salzinger, S., Feldman, R. S., Hammer, M., \& Rosario, M. (1993). The effects of physical abuse on children's social relationships. Child Development, 64(1), 169-187.

Sebba, J., Berridge, D., Luke, N., Fletcher, J., Bell, K., Strand, S ...O’Higgins A., (2015). The educational progress of looked after children in England: linking care and education data. Rees Centre for Research in Fostering and Education, University of Oxford and University of Bristol.

Seibert, A., \& Kerns, K. (2015). Early mother-child attachment: longitudinal prediction to the quality of peer relationships in middle childhood. International Journal of Behavioral Development, 39(2), 130-138.

Selwyn, J., \& Briheim-Crookall, L. (2017). Our lives, our care: looked after children's views on their well-being. Bristol: School for Policy Studies, University of Bristol.

Tarren-Sweeney, M. (2008). The mental health of children in out-of-home care. Current Opinion in Psychiatry, 21(4), 345-349.

Tarren-Sweeney, M., \& Vetere, A. (2014). Establishing the need for mental health services for children and young people in care, and those who are subsequently adopted. In M. Tarren-Sweeney \& A. Vetere (Eds.), Mental health services for vulnerable children and young people. London: Routledge.

Tideman, E., Vinnerljung, B., Hintze, K., \& Isaksson, A. A. (2011). Improving foster children's school achievements: promising results from a Swedish intensive study. Adoption \& Fostering, 35(1), 44-56. 
Trickett, P. K., Negriff, S., Ji, J., \& Peckins, M. (2011). Child maltreatment and adolescent development. Journal of Research on Adolescence, 21(1), 3-20.

Ungar, M. (2013). Resilience after maltreatment: the importance of social services as facilitators of positive adaptation. Child Abuse and Neglect, 37(2-3), 110-115.

van Ijzendoorn, M. H., Dijkstra, J., \& Bus, A. G. (1995). Attachment, intelligence, and language: a meta-analysis. Social Development, 4(2), 115-128.

Wentzel, K. R. (1993). Does being good make the grade? Social behavior and academic competence in middle school. Journal of Educational Psychology, 85(2), 357-364.

Wentzel, K. (1998). Social relationships and motivation in middle school: the role of parents, teachers, and peers. Journal of Educational Psychology, 90(2), 202-209.

West, P., Sweeting, H., \& Young, R. (2010). Transition matters: pupils' experiences of the primary-secondary school transition in the west of Scotland and consequences for well-being and attainment. Research Papers in Education, 25(1), 21-50.

Robin Banerjee. School of Psychology, University of Sussex, Falmer, Brighton, BN1 9QH, UK

Current themes of research:

Social and emotional development; well-being and mental health of children and adolescents; peer relationships; school based strategies to support pupils' social and emotional functioning; young people's participation in the creative arts; children's motivation and values; social cognition and theory of mind.

\section{Most relevant publications in the field of Psychology of Education:}

Banerjee, R., McLaughlin, C., Cotney, J., Roberts, L., \& Peereboom, C. (2016). Promoting emotional health, wellbeing, and resilience in primary schools. Cardiff: Public Policy Institute of Wales.

Banerjee, R., Weare, K., \& Farr, W. (2014). Working with 'Social and Emotional Aspects of Learning' (SEAL): associations with school ethos, pupil social experiences, attendance, and attainment. British Educational Research Journal, 40, 718-742.

$\mathrm{Ku}$, L., Dittmar, H., \& Banerjee, R. (2014). To have or to learn: the effects of materialism on British and Chinese children's learning. Journal of Personality and Social Psychology, 106, 803-821.

Leeves, S., \& Banerjee, R. (2014). Childhood social anxiety and social support-seeking: distinctive links with perceived support from teachers. European Journal of Psychology of Education, 29, 43-62.

$\mathrm{Ku}$, L., Dittmar, H., \& Banerjee, R. (2012). Are materialistic teenagers less motivated to learn? Cross-sectional and longitudinal evidence from UK and Hong Kong. Journal of Educational Psychology, 104, 74-86.

Helen Drew. School of Psychology, University of Sussex, Falmer, Brighton, BN1 9QH, UK. E-mail: H.M.Drew@sussex.ac.uk

Current themes of research:

Risk and protective factors for changes in mental health and well-being across transition. Comparisons of children in the care system (looked-after) with children who are not looked-after. The associations between relationships with peers and adults, social activities, psychological factors such as self-esteem and self-efficacy, and well-being and mental health outcomes. The role of schools and virtual schools in supporting better outcomes for looked-after children.

Most relevant publications in the field of Psychology of Education:

This is my first paper submitted for publication. 